\title{
Association between Muscle Loss and Urinary Incontinence in Elderly Korean Women
}

\author{
Hyun-Jung Park, Se-Ryung Choo, Sang-Hyuk Kim, Hyun-Ki Lee, Ki Young Son* \\ Department of Family Medicine, Seoul National University Hospital, Seoul, Korea
}

\section{ABSTRACT}

Background: Incontinence and muscle loss are important senior health issues. Nevertheless, there are no available domestic or international studies on the association between urinary incontinence and muscle loss. The aim of this study was to investigate the association between muscle loss and urinary incontinence in elderly Korean woman.

Methods: Korean women $(1,313) \geq 65$ years of age whose complete body composition data were collected using dual X-ray absorptiometry were analyzed from the Fourth Korean National Health and Nutritional Examination Surveys. Class I and II losses of the appendicular, truncal, and total muscle mass were defined using adjustments for weight and height. Each participant's incontinence status was collected using constructed questionnaires. Multiple logistic regression was performed to examine the association between muscle loss and incontinence.

Results: On the basis of physician-diagnosed incontinence, weight- and height-adjusted muscle loss showed no association with urinary incontinence (weight-adjusted muscle loss: class I adjusted odds ratio [aOR], 0.77; 95\% confidence interval [CI], 0.34 to 1.73; class II aOR, 1.37 ; $95 \%$ CI, 0.59 to 3.18 ; height-adjusted muscle loss: class I aOR, $0.51 ; 95 \%$ CI, 0.18 to 1.51 ; class II aOR, $1.86 ; 95 \%$ CI, 0.22 to 15.79$)$. Similar results were observed for truncal muscle and total muscle mass as well as self-reported urinary incontinence.

Conclusion: Our study found no association between urinary incontinence and appendicular, truncal, and total muscle loss in elderly Korean women.

Keywords: Muscle Atrophy; Skeletal Muscle; Urinary Incontinence; Aged

Received: August 31, 2013, Accepted: December 3, 2014

*Corresponding Author: Ki Young Son

Tel: +82-2-2072-4039, Fax:+82-2-766-3276, E-mail: mdsky75@snu.ac.kr

Korean Journal of Family Medicine

Copyright (C) 2015 The Korean Academy of Family Medicine

This is an open-access article distributed under the terms of the Creative Commons Attribution Non-Commercial License (http://creativecommons.org/licenses/by-nc/3.0) which permits unrestricted noncommercial use, distribution, and reproduction in any medium, provided the original work is properly cited. 


\section{INTRODUCTION}

Korea currently has one of the fastest aging populations. In 2005, 9.1\% of the Korean population was $\geq 65$ years of age. It has been predicted that in $2020,15.7 \%$ of the population will be $\geq 65$ years, and in 2030, this figure will reach $24.1 \%$. ${ }^{1)}$ Therefore, public healthcare for those who are $\geq 65$ years is becoming serious and research on this issue is increasing. ${ }^{2)}$

Research has shown that the elderly Korean population has decreased bone mineral density as well as an increased fat mass with time. ${ }^{2,3)}$ As a result, there has been a recent increase in attention on sarcopenia.

Sarcopenia is defined as a loss of muscle mass and decreased muscle strength or physical performance with increasing age. These effects cause comorbidities and even death. ${ }^{1,45}$ Muscle mass loss is related to an increase in falls, trauma, physical performance disability, hospital admission rates, and decreased quality of life and mortality. ${ }^{1,2,6,7)}$ Until now, there have been no standard criteria for muscle mass loss. However, using different definitions of muscle loss, previous studies have shown that decreases in muscle mass and strength cause serious chronic diseases such as insulin resistance, metabolic syndrome, ${ }^{1)}$ depression, ${ }^{8)}$ osteoarthritis, ${ }^{4)}$ cardiovascular disease, ${ }^{9)}$ and osteoporosis. ${ }^{10)}$

Muscle mass loss is related to the aging process throughout the whole body as evidenced by decreases in growth and sex hormone levels, neuromuscular changes, increases in blood inflammation markers, decreases in protein intake, smoking, increases in oxidative stress, increases in fat mass, and decreases in physical activity. ${ }^{11)}$ Although most previous studies on muscle mass loss have focused on appendicular skeletal muscle quality, mass, and strength, decreased muscle mass is understood as a systemic whole-body change.

One of every four women in Korean has urinary incontinence ${ }^{12)}$ that is specifically related to aging. Urinary incontinence affects an individual's quality of life, especially their physical, social, and psychological health statuses. ${ }^{13)}$ Furthermore, urinary incontinence not only increases the incidence of chronic physical diseases including urinary infections, sores, falls, and fractures, ${ }^{14)}$ but also increases the percentage of mental diseases such as low self-esteem, depression, and sexual dysfunction. ${ }^{13)}$ One of the pathogeneses of urinary incontinence is detrusor muscle dysfunction; as a result, increases in residual urine after voiding and overflow urinary incontinence may occur. Stress urinary incontinence occurs in the presence of urethral sphincter dysfunction and a decrease in urethral sphincter pressure. ${ }^{15)}$ In a study of pelvic architecture in patients with urinary incontinence, an elderly group showed decreased pelvic muscle mass along with decreased general muscle mass. Moreover, atrophy and weakness of the pelvic muscles induces changes in pelvic architecture angle and results in urinary incontinence. ${ }^{16)}$ Based on a previous study of urinary incontinence, we assumed that urinary incontinence is associated with muscle mass loss because pelvic muscle and architecture play important roles in the pathogenesis of urinary incontinence.

There is a lack of domestic and international studies of the correlation between urinary incontinence and muscle mass, so more research is needed due to the clinical importance of these diseases. The purpose of this study is to analyze the relationship between a decrease in appendicular skeletal, trunk, and total muscle masses and urinary incontinence using the Korean National Health and Nutrition Examination Survey (KNHNES). 


\section{METHODS}

\section{Study Population}

The study design was cross-sectional and we used 2-year data from the KNHANES (KHANES IV; July 2008 to December 2009) supported by the Ministry of Health and Welfare and Korea Centers for Disease Control and Prevention. The KNHANES consists of a health interview survey, health behavior survey, nutrition survey, and health examinations of children, adolescents, and adults that were conducted regularly since 1998 by the Korea Centers for Disease Control and Prevention to produce a broad range of descriptive health and nutritional statistics for the population's sex and age subdomains. The KNHANES IV contains probability samples representative of the entire country that were collected using a rolling survey sampling design method.

Of the 20,277 patients profiled in the KNHANES IV, 9,213 were men and 11,064 were women. Of the men, only $38(0.5 \%)$ responded that they had urinary incontinence symptoms and 20 participants $(0.27 \%)$ were diagnosed with urinary incontinence by a doctor. Considering the low prevalence and gender differences in the pathogenesis, the men were excluded from this study. Only women aged $\geq 65$ years (1,969 participants) were included in this study according to the World Health Organization definition about the aged. Of these participants, 1,313 underwent both a urinary incontinence survey and dual-energy X-ray absorptiometry (DXA) examinations and were thus deemed eligible for the study (Figure 1).

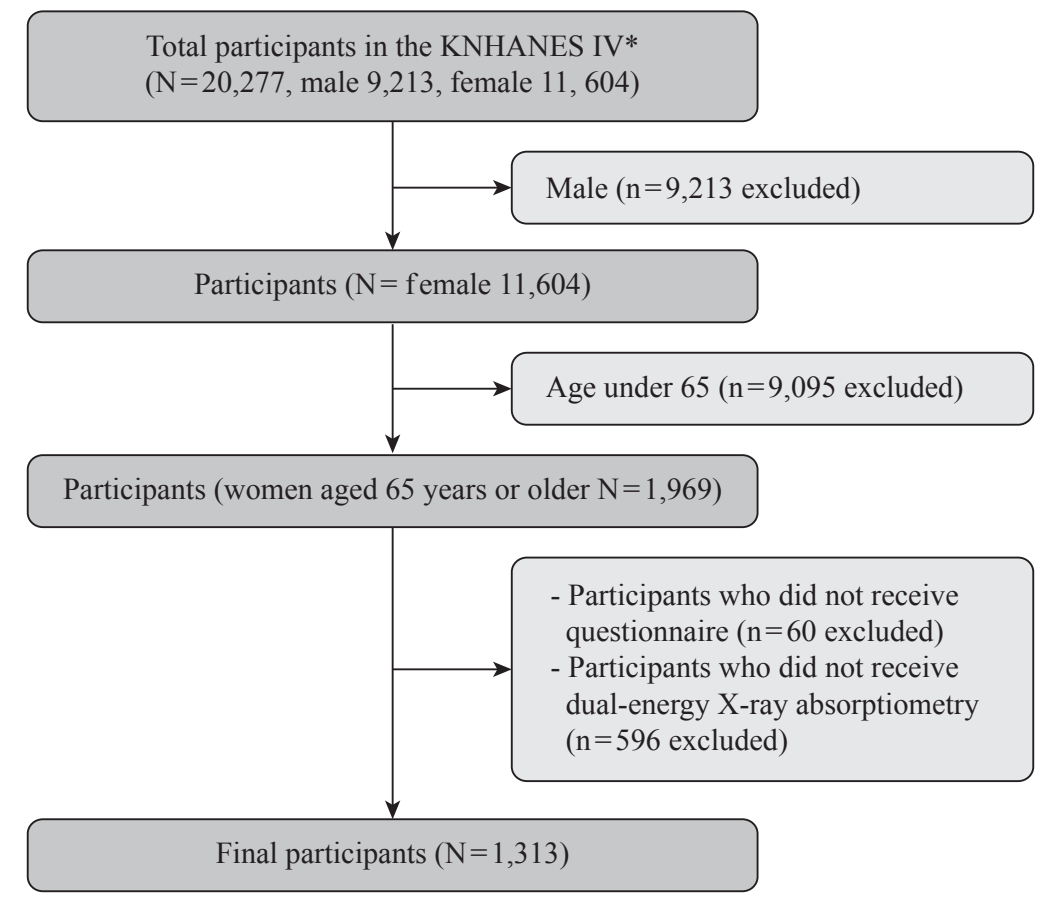

Figure 1. Flow diagram of inclusion or exclusion of study participants. *The Fourth Korean National Health and Nutrition Examination (KNHANES IV, 2008 July-2009). 


\section{Appendicular Skeletal and Total Muscle Mass Loss}

Appendicular skeletal muscle and fat masses were measured using DXA of 2-year data from the KNHANES IV (July 2008 to December 2009). The cutoff values for muscle mass loss were based on the prevalence of sarcopenia and sarcopenic obesity in the Korean population by Kim et al. ${ }^{17)}$ The cutoff values of class I and II muscle mass loss were determined to be $25.6 \%$ and $23.0 \%$, respectively, by the weight-adjusted muscle loss (WAML) definition and $5.38 \mathrm{~kg} / \mathrm{m}^{2}$ and $4.59 \mathrm{~kg} / \mathrm{m}^{2}$, respectively, by the height-adjusted muscle loss (HAML) definition. ${ }^{17,18)}$

\section{Truncal and Total Muscle Mass}

Truncal and total muscle mass were measured using DXA as described above. Total muscle mass refers to the muscle mass of the entire body but the head. Truncal and total muscle masses were analyzed as continuous and quartile variables, respectively, adjusted by height and weight.

\section{Urinary Incontinence}

Urinary incontinence was defined using the health survey data of the KNHANES IV. Each of the urinary incontinence questions was answered as "yes" or "no." Self-reported urinary incontinence was determined according to the participants' answers ("Have you ever suffered from urinary incontinence?") and urinary incontinence was diagnosed by a doctor using a structured questionnaire (“Do you have urinary incontinence?").

\section{Variable Definition}

The following health examination and interview data were retrieved from the KNHANES IV. According to previous studies, age is the most important variable of urinary incontinence. ${ }^{19)}$ As such, it was analyzed here as a continuous variable. Body mass index (BMI) was calculated as weight in kilograms divided by the square of the height in meters. The cutoff BMI value was $25 \mathrm{~kg} / \mathrm{m}^{2}$ in our study. ${ }^{5,6)}$ Subjective health status was reclassified from the five-point scale ranging from very good to very poor of the KNHANES IV to a three-point scale of good, average, and poor. Pregnancy experience (history of delivering one or more baby) was classified as yes or no and activity limitation was used to answer yes or no using the questionnaire ("Do you have limitations in daily life or social activities because of your current health problems or physical or mental disability?"). According to previous studies about the risk factors of urinary incontinence, neurological diseases, and co-morbidities, abdominal and urological surgical history as well as medication history were the main causes of urinary incontinence. ${ }^{20,21)}$

Comorbidities were assessed using yes or no answers to questions on the survey of the prevalence of stroke, depression, diabetes, arthritis, and osteoporosis in the KNHANES IV. Profession was classified as a binary variable divided into an economically active person and unemployed or economically inactive person depending on the current economic activities. At-risk alcohol drinking was defined as more than seven drinks per week or three drinks on any single day depending on the standard drinking 
according to the criteria established by the Alcohol Research Center National Institute on Alcohol Abuse \& Alcoholism clinicians' guide in 2005, while the alcohol consumption amount was classified as a binary variable according to the at-risk drink definition. ${ }^{22)}$ Smoking status information was collected by asking whether participants were never, past, or current smokers. Marital status was recorded as with or without spouse (the former included living together, while the latter meant separated, divorced, widowed, or single). Income was assessed using the personal income quartile of the KNHANES IV. Regular exercises were evaluated as the number of moderate-intensity physical activity sessions per week divided into less than three times a week and more than three times a week. Hormone replacement was assessed using a yes or no question and education level was reclassified into four categories: $<6$ years, $\geq 6$ to $<9$ years, $\geq 9$ to $<12$ years, and $\geq 12$ years.

\section{Statistical Analysis}

The participants' anthropometric characteristics are described as means and SDs. The participants' general characteristics are expressed as numbers and percentages. To compare intergroup differences, continuous variables were tested using analysis of variance and the chi square test to detect differences in the distribution of categorical variables.

The association between appendicular skeletal, truncal, and total muscle mass and urinary incontinence, adjusted for covariates, was analyzed using multivariate logistic regression analysis. Potential covariates included age, occupation, education level, self-reported health status, pregnancy experience, activity limitation, body mass index, and depression. The group without urinary incontinence was used as the reference group. Odds ratio (OR) and 95\% confidence interval (95\% CI) were obtained from multivariate analysis.

Values of $\mathrm{P}<0.05$ were considered statistically significant in all analyses. To estimate the significance of the trend, the truncal and total muscle mass variable was considered a continuous variable in the trend analysis. All statistical results were based on two-sided tests. Data were analyzed using Stata ver. 12.1 software (Stata Co., College Station, TX, USA).

\section{RESULTS}

A total of 1,313 Korean women $\geq 65$ years of age were included in this study: of them, 1,139 $(86.8 \%)$ did not have urinary incontinence. Of the 174 participants $(13.2 \%)$ with urinary incontinence symptoms, 41 (3.1\%) were diagnosed by a doctor and 133 reported that they were affected by urinary incontinence despite the lack of a diagnosis.

\section{Participants'Anthropometric Characteristics}

The participants' anthropometric characteristics are shown in Table 1. Patients with urinary incontinence 
showed higher values of height ( $\mathrm{P}=0.006)$, weight $(\mathrm{P}=0.003)$, abdominal circumference $(\mathrm{P}<0.001)$, appendicular skeletal muscle mass ( $\mathrm{P}=0.009)$, truncal muscle mass $(\mathrm{P}=0.002)$, and total muscle mass $(\mathrm{P}=0.001)$ than the control group. However, there was no association between urinary incontinence and BMI, total body fat, height- or weight-adjusted appendicular skeletal muscle mass, height- or weight-adjusted truncal muscle mass, or height- or weight-adjusted total muscle mass (Table 1).

Table 1. Anthropometric characteristics of the participants with and without self-reported or doctor-diagnosed urinary incontinence

\begin{tabular}{|c|c|c|c|c|c|c|c|}
\hline \multirow{2}{*}{$\begin{array}{l}\text { Anthropometric } \\
\text { characteristic }\end{array}$} & \multicolumn{2}{|c|}{ Normal $(\mathrm{n}=1,139)$} & \multicolumn{2}{|c|}{$\begin{array}{l}\text { Self-reported urinary } \\
\text { incontinence }(n=133)\end{array}$} & \multicolumn{2}{|c|}{$\begin{array}{l}\text { Diagnosed urinary } \\
\text { incontinence }(n=41)\end{array}$} & \multirow[t]{2}{*}{ P-value } \\
\hline & Mean \pm SD & Range & Mean \pm SD & Range & Mean \pm SD & Range & \\
\hline Age (y) & $72.5 \pm 5.5$ & $65-91$ & $71.6 \pm 5.1$ & $65-89$ & $72.3 \pm 5.2$ & $65-84$ & 0.236 \\
\hline Height (cm) & $150.3 \pm 5.8$ & $130.5-168.8$ & $151.7 \pm 5.7$ & $137.2-166.7$ & $151.9 \pm 5.6$ & $141.3-163.7$ & 0.006 \\
\hline Weight (kg) & $54.1 \pm 8.9$ & $31.1-96.5$ & $56.1 \pm 8.7$ & $39.1-79.6$ & $57.5 \pm 7.6$ & $40.7-72.3$ & 0.003 \\
\hline Waist circumference $(\mathrm{cm})$ & $82.5 \pm 9.8$ & $36.2-124$ & $84.6 \pm 10.0$ & $60.1-113.5$ & $88.0 \pm 9.3$ & $71.5-105.5$ & $<0.001$ \\
\hline Body mass index $\left(\mathrm{kg} / \mathrm{m}^{2}\right)$ & $23.9 \pm 3.4$ & $14.7-40.8$ & $24.3 \pm 3.3$ & $17.9-31.9$ & $24.9 \pm 2.5$ & $19.2-29.8$ & 0.083 \\
\hline Total body fat (\%) & $33.2 \pm 5.8$ & $12.0-48.9$ & $33.7 \pm 5.5$ & $20.4-47.5$ & $34.9 \pm 4.4$ & $25.8-44.4$ & 0.106 \\
\hline ASM (kg) & $13.4 \pm 1.8$ & $8.7-21.0$ & $13.8 \pm 2.1$ & $9.6-19.6$ & $14.0 \pm 1.9$ & $10.1-19.5$ & 0.009 \\
\hline Total trunk muscle mass $(\mathrm{kg})$ & $17.6 \pm 2.4$ & $11.2-29.6$ & $18.2 \pm 2.3$ & $12.9-24.2$ & $18.6 \pm 2.5$ & $14.8-24.4$ & 0.002 \\
\hline Total muscle mass (kg) & $31.8 \pm 4.1$ & $20.1-51.4$ & $32.8 \pm 4.2$ & $23.0-42.7$ & $33.4 \pm 4.1$ & $26.3-43.5$ & 0.001 \\
\hline ASM/wt (\%) & $25.1 \pm 2.8$ & $17.4-35.1$ & $24.9 \pm 2.9$ & $19.4-33.1$ & $24.5 \pm 2.5$ & $20.2-32.6$ & 0.317 \\
\hline $\mathrm{ASM} / \mathrm{ht}^{2}\left(\mathrm{~kg} / \mathrm{m}^{2}\right)$ & $5.9 \pm 0.7$ & $4.3-9.7$ & $6.0 \pm 0.7$ & $4.5-8.0$ & $6.1 \pm 0.7$ & $4.5-8.1$ & 0.389 \\
\hline TRM/wt (\%) & $32.9 \pm 2.9$ & $25.6-43.4$ & $32.8 \pm 2.7$ & $26.6-39.8$ & $32.5 \pm 2.8$ & $26.7-38.9$ & 0.588 \\
\hline $\mathrm{TRM} / \mathrm{ht}^{2}\left(\mathrm{~kg} / \mathrm{m}^{2}\right)$ & $7.8 \pm 0.9$ & $5.5-13.7$ & $7.9 \pm 0.8$ & $6.2-9.9$ & $8.1 \pm 0.9$ & $5.9-9.8$ & 0.094 \\
\hline TM/wt (\%) & $59.3 \pm 5.1$ & $45.8-79.6$ & $59.0 \pm 5.0$ & $47.1-72.7$ & $58.3 \pm 4.5$ & $49.4-67.5$ & 0.416 \\
\hline $\mathrm{TM} / \mathrm{ht}^{2}\left(\mathrm{~kg} / \mathrm{m}^{2}\right)$ & $14.0 \pm 1.4$ & $10.7-23.8$ & $14.2 \pm 1.4$ & $11.2-17.7$ & $14.5 \pm 1.4$ & $11.2-18.2$ & 0.091 \\
\hline
\end{tabular}

Values are presented as mean $\pm \mathrm{SD}$ and range. The data were analyzed by analysis of variance.

ASM: appendicular skeletal muscle mass, ht: height, wt: weight, TRM: total muscle mass, TM: total muscle mass.

\section{General Characteristics of Participants}

The following parameters were statistically significant: currently employed $(P=0.01)$, pregnancy experience $(\mathrm{P}<0.001)$, education level $(\mathrm{P}=0.02)$ and subjective self-reported heath status. The percentage of responses involving activity limitations was higher in urinary incontinence group than in the control group $(\mathrm{P}=0.009)$. Of the chronic diseases, only depression was statistically significant $(\mathrm{P}<0.001)$. The following parameters were not statistically significant: at-risk drinking, smoking status, spouse or not, income level, regular exercise, hormone replacement, and chronic diseases including stroke, diabetes, arthritis, and osteoporosis (Table 2). 
Table 2. General characteristics of the participants with and without self-reported or doctor-diagnosed urinary incontinence

\begin{tabular}{|c|c|c|c|c|c|}
\hline Characteristic & Category & Normal $(\mathrm{n}=1,139)$ & $\begin{array}{l}\text { Self-reported } \\
\text { incontinence } \\
(\mathrm{n}=133)\end{array}$ & $\begin{array}{l}\text { Diagnosed } \\
\text { incontinence } \\
(\mathrm{n}=41)\end{array}$ & P-value \\
\hline \multirow[t]{2}{*}{ Occupation } & Currently working & $356(31.4)$ & $37(27.8)$ & $4(9.8)$ & 0.01 \\
\hline & Not working & $778(68.6)$ & $96(72.2)$ & $37(90.2)$ & \\
\hline \multirow[t]{2}{*}{ At-risk drinking ${ }^{*}$} & Yes & $1,118(98.2)$ & $133(100.0)$ & $40(97.6)$ & 0.272 \\
\hline & No & $21(1.8)$ & 0 & $1(2.4)$ & \\
\hline \multirow[t]{3}{*}{ Cigarette smoking } & Current & $62(5.5)$ & $10(7.5)$ & $2(4.9)$ & 0.776 \\
\hline & Ex-smoker & $73(6.4)$ & $6(4.5)$ & $2(4.9)$ & \\
\hline & None & $1,001(88.1)$ & $117(88.0)$ & $37(90.2)$ & \\
\hline \multirow[t]{2}{*}{ Marital status $^{\dagger}$} & Spouse & $511(44.9)$ & $63(47.4)$ & $26(63.4)$ & 0.06 \\
\hline & No spouse & $627(55.1)$ & $70(52.6)$ & $15(36.6)$ & \\
\hline \multirow[t]{4}{*}{ Income } & 1st quartile & $270(24.3)$ & $28(21.5)$ & $11(29.0)$ & 0.228 \\
\hline & 2nd quartile & $291(26.2)$ & $40(30.8)$ & $6(15.8)$ & \\
\hline & 3rd quartile & $263(23.7)$ & 35 (26.9) & $14(36.8)$ & \\
\hline & 4th quartile & $286(25.8)$ & $27(20.8)$ & $7(18.4)$ & \\
\hline \multirow[t]{3}{*}{ Regular exercise } & None & $727(62.8)$ & $91(68.4)$ & $27(65.9)$ & 0.629 \\
\hline & $<3$ times/wk & $119(10.5)$ & $11(8.3)$ & $2(4.9)$ & \\
\hline & $\geq 3$ times/wk & $293(25.7)$ & $31(23.3)$ & $12(29.3)$ & \\
\hline \multirow[t]{2}{*}{$\begin{array}{l}\text { Hormone replace } \\
\text { therapy }\end{array}$} & Yes & $68(6.4)$ & $5(4.2)$ & $6(15.0)$ & 0.054 \\
\hline & No & $996(93.6)$ & $114(95.8)$ & $34(85.0)$ & \\
\hline \multirow[t]{4}{*}{ Education } & Elementary $(<6$ y) & $1,021(90.0)$ & $117(88.0)$ & $31(75.6)$ & 0.024 \\
\hline & Middle $(6-9 y)$ & $54(4.8)$ & $9(6.8)$ & $5(12.2)$ & \\
\hline & High $(9-12$ y) & $42(3.7)$ & $4(3.0)$ & $5(12.2)$ & \\
\hline & Post-high (>12 y) & $17(1.5)$ & $3(2.2)$ & 0 & \\
\hline \multirow[t]{3}{*}{$\begin{array}{l}\text { Self-reported } \\
\text { heath status }\end{array}$} & Good & $313(27.6)$ & $31(23.3)$ & $6(14.6)$ & 0.025 \\
\hline & Fair & $268(23.6)$ & $23(17.3)$ & $7(17.1)$ & \\
\hline & $\mathrm{Bad}$ & $553(48.8)$ & $79(59.4)$ & $28(68.3)$ & \\
\hline \multirow[t]{2}{*}{ Pregnancy experience } & Yes & $1,054(99.0)$ & $112(93.3)$ & $39(97.5)$ & $<0.001$ \\
\hline & No & $11(1.0)$ & $8(6.8)$ & $1(2.5)$ & \\
\hline \multirow[t]{2}{*}{ Activity limitation } & Yes & $532(46.9)$ & $80(60.1)$ & $23(56.1)$ & 0.009 \\
\hline & No & $603(53.1)$ & $53(39.9)$ & $18(43.9)$ & \\
\hline \multicolumn{6}{|l|}{ Chronic disease } \\
\hline \multirow[t]{2}{*}{ Stroke } & Yes & $51(4.5)$ & $8(6.0)$ & $4(9.8)$ & 0.235 \\
\hline & No & $1,088(95.5)$ & $125(94.0)$ & $37(90.2)$ & \\
\hline \multirow[t]{2}{*}{ Depression } & Yes & $232(20.4)$ & $49(36.8)$ & $13(31.7)$ & $<0.001$ \\
\hline & No & 907 (79.6) & $84(63.2)$ & $28(68.3)$ & \\
\hline \multirow[t]{2}{*}{ Diabetes } & Yes & $187(16.4)$ & $27(20.3)$ & $12(29.3)$ & 0.062 \\
\hline & No & $952(83.6)$ & $106(79.7)$ & $29(70.7)$ & \\
\hline \multirow[t]{2}{*}{ Arthritis } & Yes & $602(52.8)$ & $79(59.4)$ & $26(63.4)$ & 0.164 \\
\hline & No & $537(47.2)$ & $54(40.6)$ & $15(36.6)$ & \\
\hline \multirow[t]{2}{*}{ Osteoporosis } & Yes & 361 (31.7) & $54(40.6)$ & $17(41.5)$ & 0.058 \\
\hline & No & $778(68.3)$ & $79(59.4)$ & $24(58.5)$ & \\
\hline
\end{tabular}

Values are presented as number of cases (\%). The data were analyzed using the chi-square test.

*At-risk alcohol drinking means more than three drinks in a day or more than seven drinks in a week for healthy women according to the National Institute on Alcohol Abuse \& Alcoholism clinicians' guide. 'Marital status is 
divided into 'spouse', which includes living together, and 'no spouse', which means separated, divorced, widowed, or single on the Fourth Korea National Health and Nutrition Examination Survey. ${ }^{*}$ Regular exercise means the number of days of moderate-intensity physical activity during the week on the Fourth Korea National Health and Nutrition Examination Survey.

\section{Appendicular Skeletal Muscle Mass and Urinary Incontinence}

Both WAML and HAML were not associated with urinary incontinence in the 133 self-reported urinary incontinence participants. Those with WAML class I had an adjusted OR (aOR) of 1.01 and 95\% CI of 0.64 to 1.60 , while those with class IIa had an aOR of 0.81 and 95\% CI of 0.46 to 1.42 . Those with HAML class I had an aOR of 0.80 and $95 \%$ CI of 0.47 to 1.38 , while those with class II had an aOR of 1.12 and $95 \%$ CI of 0.14 to 9.14 . The 41 participants diagnosed with urinary incontinence by a doctor had similar results. Those with WAML class I had an aOR of 0.77 and $95 \%$ CI of 0.34 to 1.73 , while those with class II had an aOR of 1.37 and $95 \%$ CI of 0.59 to 3.18. Those with HAML class I had an aOR of 0.51 and $95 \%$ CI of 0.18 to 1.51 , while those with class II had an aOR of 1.86 and $95 \%$ CI of 0.22 to 15.79 . The differences were not statistically significant (Table 3 ).

Table 3. Multivariate analysis of muscle loss and urinary incontinence

\begin{tabular}{lcccc}
\hline \multicolumn{1}{c}{ Urinary incontinence } & Self-reported $(\mathrm{n}=133)$ & P-value & Diagnosed $(\mathrm{n}=41)$ & P-value \\
\hline $\begin{array}{l}\text { Appendicular skeletal mass } \\
\text { Weight-adjusted definition }\end{array}$ & & & & \\
$\quad$ Normal & 1 & & 1 & 0.524 \\
$\quad$ Class I muscle loss & $1.01(0.64-1.60)$ & 0.954 & $0.77(0.34-1.73)$ & 0.459 \\
$\quad$ Class II muscle loss & $0.81(0.46-1.42)$ & 0.458 & $1.37(0.59-3.18)$ & 0.226 \\
Height-adjusted definition & & & & 1 \\
$\quad$ Normal & 1 & & $0.51(0.18-1.51)$ & 0.570 \\
Class I muscle loss & $0.80(0.47-1.38)$ & 0.425 & $1.86(0.22-15.79)$ & \\
$\quad$ Class II muscle loss & $1.12(0.14-9.14)$ & 0.917 & & 0.696 \\
Continuous variable & & & $0.97(0.85-1.11)$ & 0.294 \\
ASM weight-adjusted & $1.03(0.95-1.11)$ & 0.465 & $1.33(0.78-2.28)$ & \\
ASM height-adjusted & $1.18(0.85-1.63)$ & 0.318 & & \\
\hline
\end{tabular}

Values are presented as OR (95\% CI). ORs and 95\% CI on multivariate analysis were determined. The data were analyzed by logistic regression adjusted for age, occupation, education, self-reported heath status, pregnancy experience, menopause, activity limitation, body mass index, and depression. The cutoff values of class I and class II muscle loss were determined to be $25.6 \%$ and $23.0 \%$, respectively, by the weight-adjusted definition and $5.38 \mathrm{~kg} /$ $\mathrm{m}^{2}$ and $4.59 \mathrm{~kg} / \mathrm{m}^{2}$, respectively, by the height-adjusted definition.

OR: odds ratio, CI: confidence interval, ASM: appendicular skeletal muscle mass.

\section{Truncal and Total Muscle Mass and Urinary Incontinence}

Truncal and total muscle mass were classified into quartiles after adjustment for height and weight. On the basis of self-reported urinary incontinence, weight-adjusted truncal muscle loss showed no 
association with urinary incontinence $(\mathrm{P}$ for trend $=0.981$ ) and similar results were observed for heightadjusted truncal muscle loss ( $\mathrm{P}$ for trend $=0.412$ ). Similar results were observed for weight-adjusted truncal muscle loss $(\mathrm{P}$ for trend $=0.757)$ and height-adjusted trunk muscle loss $(\mathrm{P}$ for trend $=0.225)$ in participants with doctor-diagnosed urinary incontinence. In addition, our study found no association between urinary incontinence and WAML or HAML (Table 4).

Table 4. Multivariate analysis of trunk and total muscle mass and urinary incontinence

\begin{tabular}{|c|c|c|c|c|c|c|}
\hline \multirow{2}{*}{ Urinary incontinence } & \multicolumn{3}{|c|}{ Self-reported $(\mathrm{n}=133)$} & \multicolumn{3}{|c|}{ Diagnosed $(n=41)$} \\
\hline & Odds ratio & $95 \% \mathrm{CI}$ & P for trend & Odds ratio & $95 \% \mathrm{CI}$ & P for trend \\
\hline \multicolumn{7}{|l|}{ Trunk muscle mass } \\
\hline Not adjusted & 1.16 & $1.02-1.22$ & 0.022 & 1.15 & $0.99-1.34$ & 0.065 \\
\hline Weight-adjusted definition & & $0.83-1.21$ & 0.981 & & $0.70-1.30$ & 0.757 \\
\hline 1st quartile & 1 & & & 1 & & \\
\hline 2nd quartile & 0.74 & & & 1.27 & & \\
\hline 3rd quartile & 1.27 & & & 0.59 & & \\
\hline 4th quartile & 0.78 & & & 1.13 & & \\
\hline Height-adjusted definition & & $0.89-1.33$ & 0.412 & & $0.88-1.71$ & 0.225 \\
\hline 1st quartile & 1 & & & 1 & & \\
\hline 2nd quartile & 1.35 & & & 1.14 & & \\
\hline 3rd quartile & 0.76 & & & 1.99 & & \\
\hline 4th quartile & 1.65 & & & 1.63 & & \\
\hline \multicolumn{7}{|l|}{ Total muscle mass } \\
\hline Not adjusted & 1.07 & $1.02-1.13$ & 0.011 & 1.08 & $0.99-1.18$ & 0.07 \\
\hline Weight-adjusted definition & & $0.89-1.32$ & 0.406 & & $0.96-0.16$ & 0.822 \\
\hline 1st quartile & 1 & & & 1 & & \\
\hline 2nd quartile & 1.49 & & & 0.56 & & \\
\hline 3rd quartile & 1.10 & & & 0.51 & & \\
\hline 4th quartile & 1.49 & & & 0.99 & & \\
\hline Height-adjusted definition & & $0.99-1.47$ & 0.061 & & $0.97-1.87$ & 0.078 \\
\hline 1st quartile & 1 & & & 1 & & \\
\hline 2nd quartile & 1.41 & & & 1.43 & & \\
\hline 3rd quartile & 1.32 & & & 2.57 & & \\
\hline 4th quartile & 1.93 & & & 2.26 & & \\
\hline
\end{tabular}

Odds ratios and 95\% CI on multivariate analysis were determined. The data were analyzed by logistic regression adjusted for age, occupation, education, self-reported heath status, pregnancy experience, activity limitation, body mass index, and depression. Values are presented as continuous variables and four quartiles after adjustment for weight and height. The cutoff values of trunk muscle mass were determined to be $31.07 \%, 32.84 \%$, and $34.76 \%$, respectively, by the weight-adjusted definition and $7.01 \mathrm{~kg} / \mathrm{m}^{2}, 7.54 \mathrm{~kg} / \mathrm{m}^{2}$, and $8.18 \mathrm{~kg} / \mathrm{m}^{2}$, respectively, by the height-adjusted definition. The cutoff values of total muscle mass were determined to be $56.91 \%, 59.99 \%$, and $63.30 \%$, respectively, by the weight-adjusted definition and $12.86 \mathrm{~kg} / \mathrm{m}^{2}, 13.83 \mathrm{~kg} / \mathrm{m}^{2}$, and $14.88 \mathrm{~kg} / \mathrm{m}^{2}$, and 15.86 $\mathrm{kg} / \mathrm{m}^{2}$, respectively, by the height-adjusted definition.

CI: confidence interval. 


\section{DISCUSSION}

This study has important meaning because it is the first domestic or international examination of the association between appendicular skeletal, truncal, and total muscle mass and urinary incontinence. According to recent studies, $>30 \%$ of patients with urinary incontinence are not diagnosed by doctors because they do not undergo a medical checkup even though urinary incontinence symptoms affect their quality of life. ${ }^{23)}$ Therefore, we assumed that more individuals have urinary incontinence symptoms than the number diagnosed by doctors and analyzed two different groups: those diagnosed by doctors and those with urinary incontinence symptoms but no diagnosis (self-reported).

Results of multivariate analysis adjusted for confounding variables related with urinary incontinence showed no definite relationship between height- and weight-adjusted appendicular skeletal, truncal, or total muscle mass and urinary incontinence and no statistically significant difference in values.

First, since we could not control the dependent variable (urinary incontinence), the results showed no relationship between muscle mass and urinary incontinence. The EPINCONT (Epidemiology of Incontinence in the County of Nord-Trondelag) study of women in Norway showed that $50 \%$ of urinary incontinence patients had stress incontinence, 36\% had mixed incontinence, and $11 \%$ had urge incontinence. ${ }^{24)}$ The rate of stress incontinence changed by age. The rate of urge incontinence increased and mixed urinary incontinence was more prevalent than stress urinary incontinence in those elderly patients. ${ }^{25)}$ Pelvic floor or urethral sphincter muscle weakness causes stress urinary incontinence, while the main cause of urge incontinence is bladder dysfunction. ${ }^{26)}$ We could not investigate urinary incontinence types in this study. Therefore, we cannot exclude the possibility of these results of muscle mass loss because there is little influence of muscle weakness on urge or mixed incontinence in elderly women, although aging influences all types of urinary incontinence.

Second, this study used a variety of methods to measure muscle mass loss due to no standardized diagnostic criteria for it. However, we could not find a relationship between appendicular skeletal muscle mass and urinary incontinence. Additionally, we analyzed the relationship between urinary incontinence and truncal muscle mass, including pelvic muscles related to urinary incontinence, but obtained the same results.

Third, this study used simple muscle mass factors without evaluating muscle strength or physical performance in the KNHNES IV. According to previous research about the relationship between comorbidity or mortality and muscle mass or muscle strength, decreased muscle strength is the more important risk factor predicting physical disease and death. ${ }^{18,27)}$ Considering that muscle strength is the most important risk factor even after adjustment for muscle mass, it will be necessary to carefully interpret our findings of muscle mass loss only without information about muscle strength. Stav et al. ${ }^{16}$ reported on the characteristics of the pelvic structures of patients with urinary incontinence and found that their pelvic muscle masses were significantly lower, which affects the pathogenesis of urinary incontinence regardless of type. Therefore, this study might be important despite its lack of significant results.

Fourth, BMI is the single independent risk factor of urinary incontinence; even after controlling for 
relevant variables, it influences urinary incontinence incidence and severity. ${ }^{20,28-30)}$ However, it is already known that BMI is not a reliable indicator of obesity in the elderly. ${ }^{27}$ Previous studies used body fat mass and abdominal circumference rather than BMI to define obesity. Therefore, we did additional analyses of total body fat mass and abdominal circumference and used BMI cutoff values of 27.5 and 23 but found no significant differences in the results.

Finally, this study had a small sample size. Of the 1,131 participants, only 41 were diagnosed with urinary incontinence by a doctor. Therefore, our data will likely fail to sufficiently reflect the characteristics of the general population and may have limited usefulness on statistical analysis.

In conclusion, urinary incontinence is not significantly associated with muscle mass loss. Further research is required to confirm the associations observed in this study. Studies examining the relevance of muscle mass loss by urinary incontinence type are necessary, as are those that focus on explaining the relationship between musculoskeletal conditions and urinary incontinence by considering muscle strength and physical performance as well as muscle mass loss.

\section{CONFLICT OF INTEREST}

No potential conflict of interest relevant to this article was reported.

\section{REFERENCES}

1. Kim JH, Hwang Bo Y, Hong ES, Ohn JH, Kim CH, Kim HW, et al. Investigation of sarcopenia and its association with cardiometabolic risk factors in elderly subjects. J Korean Geriatr Soc 2010;14:121-30.

2. Hong S, Choi WH. Clinical and physiopathological mechanism of sarcopenia. Korean J Med 2012;83:444-54.

3. Bijlsma AY, Meskers CG, Westendorp RG, Maier AB. Chronology of age-related disease definitions: osteoporosis and sarcopenia. Ageing Res Rev 2012;11:320-4.

4. Lee S, Kim TN, Kim SH. Sarcopenic obesity is more closely associated with knee osteoarthritis than is nonsarcopenic obesity: a cross-sectional study. Arthritis Rheum 2012;64:3947-54.

5. Roubenoff R. Sarcopenic obesity: does muscle loss cause fat gain?: lessons from rheumatoid arthritis and osteoarthritis. Ann N Y Acad Sci 2000;904:553-7.

6. Zamboni M, Mazzali G, Fantin F, Rossi A, Di Francesco V. Sarcopenic obesity: a new category of obesity in the elderly. Nutr Metab Cardiovasc Dis 2008;18:388-95.

7. Fielding RA, Vellas B, Evans WJ, Bhasin S, Morley JE, Newman AB, et al. Sarcopenia: an undiagnosed condition in older adults. Current consensus definition: prevalence, etiology, and consequences. International working group on sarcopenia. J Am Med Dir Assoc 2011;12:249-56.

8. Kim NH, Kim HS, Eun CR, Seo JA, Cho HJ, Kim SG, et al. Depression is associated with sarcopenia, not central obesity, in elderly korean men. J Am Geriatr Soc 2011;59:2062-8. 
9. Stephen WC, Janssen I. Sarcopenic-obesity and cardiovascular disease risk in the elderly. J Nutr Health Aging 2009;13:460-6.

10. Lima RM, Bezerra LM, Rabelo HT, Silva MA, Silva AJ, Bottaro M, et al. Fat-free mass, strength, and sarcopenia are related to bone mineral density in older women. J Clin Densitom 2009;12:35-41.

11. Ahn N, Kim K. Strengthening exercise for prevention of sarcopenia during the aging process. Korean J Obes 2012;21:187-96.

12. Lee KS, Sung HH, Na S, Choo MS. Prevalence of urinary incontinence in Korean women: results of a National Health Interview Survey. World J Urol 2008;26:179-85.

13. Coyne KS, Sexton CC, Irwin DE, Kopp ZS, Kelleher CJ, Milsom I. The impact of overactive bladder, incontinence and other lower urinary tract symptoms on quality of life, work productivity, sexuality and emotional well-being in men and women: results from the EPIC study. BJU Int 2008;101:1388-95.

14. Brown JS, Vittinghoff E, Wyman JF, Stone KL, Nevitt MC, Ensrud KE, et al. Urinary incontinence: does it increase risk for falls and fractures?: study of Osteoporotic Fractures Research Group. J Am Geriatr Soc 2000;48:721-5.

15. Resnick, NM, Elbadawi, A, Yalla, SV. Age and the lower urinary tract: what is normal? Neurourol Urodyn 1995; 14:577.

16. Stav K, Alcalay M, Peleg S, Lindner A, Gayer G, Hershkovitz I. Pelvis architecture and urinary incontinence in women. Eur Urol 2007;52:239-44.

17. Kim YS, Lee Y, Chung YS, Lee DJ, Joo NS, Hong D, et al. Prevalence of sarcopenia and sarcopenic obesity in the Korean population based on the Fourth Korean National Health and Nutritional Examination Surveys. J Gerontol A Biol Sci Med Sci 2012;67:1107-13.

18. Hong S, Choi WH. Clinical and physiopathological mechanism of sarcopenia. Korean J Med 2012;83:444-54.

19. Dwyer PL, Lee ET, Hay DM. Obesity and urinary incontinence in women. Br J Obstet Gynaecol 1988;95:91-6.

20. Thom DH, van den Eeden SK, Brown JS. Evaluation of parturition and other reproductive variables as risk factors for urinary incontinence in later life. Obstet Gynecol 1997;90:983-9.

21. Jackson SL, Scholes D, Boyko EJ, Abraham L, Fihn SD. Urinary incontinence and diabetes in postmenopausal women. Diabetes Care 2005;28:1730-8.

22. National Institute on Alcohol Abuse and Alcoholism. Helping patients who drink too much: a clinician's guide. Rockville (MD): Department of Health \& Human Services, National Institutes of Health, National Institute on Alcohol Abuse and Alcoholism; 2005.

23. Branch LG, Walker LA, Wetle TT, DuBeau CE, Resnick NM. Urinary incontinence knowledge among community-dwelling people 65 years of age and older. J Am Geriatr Soc 1994;42:1257-62.

24. Hannestad YS, Rortveit G, Sandvik H, Hunskaar S; Norwegian EPINCONT study. Epidemiology of Incontinence in the County of Nord-Trøndelag: a community-based epidemiological survey of female urinary incontinence: the Norwegian EPINCONT study: epidemiology of Incontinence in the County of Nord-Trondelag. J Clin Epidemiol 2000;53:1150-7.

25. Diokno AC, Brock BM, Brown MB, Herzog AR. Prevalence of urinary incontinence and other urological symptoms in the noninstitutionalized elderly. J Urol 1986;136:1022-5. 
Hyun-Jung Park, et al: Muscle Loss and Urinary Incontinence in Elderly Women

26. Choi JB. Urinary incontinence in women. Korean J Fam Med 2010;31:661-71.

27. Jung HW, Kim SW, Chin HJ, Kim CH, Kim KI. Skeletal muscle mass as a predictor of mortality in the elderly population. Korean J Med 2013;85:167-73.

28. Oh HS, Kim MK. Factors affecting the severity of urinary incontinence and the quality of life of women with urinary incontinence. J Korean Acad Nurs 2005;35:469-77.

29. Subak LL, Wing R, West DS, Franklin F, Vittinghoff E, Creasman JM, et al. Weight loss to treat urinary incontinence in overweight and obese women. N Engl J Med 2009;360:481-90.

30. Subak LL, Whitcomb E, Shen H, Saxton J, Vittinghoff E, Brown JS. Weight loss: a novel and effective treatment for urinary incontinence. J Urol 2005;174:190-5. 